\title{
Digestive System Lymphoma
}

National Cancer Institute

\section{Source}

National Cancer Institute. Digestive System Lymphoma. NCI Thesaurus. Code C38162.

A non-Hodgkin or Hodgkin lymphoma that arises from any part of the digestive system, with the bulk of the disease localized to that site. 